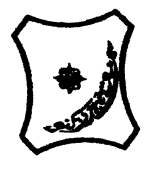

Bayero Journal of Pure and Applied Sciences, 12(1): 93 - 98

ISSN $2006-6996$

\title{
HEAVY METAL CONTENT AND MICROBIOLOGICAL QUALITY OF YAJI (COMPLEX SPICE MIXTURE) SOLD WITHIN KANO METROPOLIS
}

\author{
${ }^{* 1}$ Abdulsalam, L. and ${ }^{2}$ Usman, R. A. \\ Department Of Microbiology, Bayero University, P.M.B. 3011 Kano, Nigeria. \\ ${ }^{* 1}$ Correspondence Author: abdulsalamlatifat070@gmail.com.
}

\begin{abstract}
In recent years, food biosafety has been a priority, as such a study was carried out on the microbiological and heavy metal contents of yaji; a complex spice mixture sold within Kano metropolis. A total of nine yaji samples were purchased randomly in several retail stores within Kano metropolis and compared with 3 samples prepared in the laboratory. The result of the analysis showed that the total aerobic mesophilic count, fungal count and coliform count ranged from $3.35 \times 10^{6}->3.00 \times 10^{7} \mathrm{cfu} / \mathrm{g},<1.00 \times 10^{3}$ $9.60 \times 10^{6} \mathrm{cfu} / \mathrm{g}$, and $3.6->1100 \mathrm{MPN} / \mathrm{g}$ respectively. Staphylococcus aureus, Escherichia coli, Salmonella, Enterobacter and Klebsiella species were the bacteria isolated while Fusarium, Rhizopus and Aspergillus species were the fungi isolated from the samples. The counts obtained were higher than the maximum acceptable levels provided by the ISO and FAO. The ranges of the concentration of heavy metals in dry weight were; lead $0.001-0.003$, nickel $0.001-0.005$, copper $0.002-0.020$, zinc $0.105-0.223$, iron $0.004-$ $0.009 \mathrm{~g} / \mathrm{Kg}$. The levels of metals found in the samples were within the standard limits approved by WHO. This study showed that the samples were not contaminated with the studied heavy metals but were found to harbor microorganisms, which can pose serious health hazard to consumers. It is therefore recommended that strict hygienic measures should be taken during yaji preparation since the laboratory prepared yaji were less contaminated. Public enlightenment on the dangers of heavy metals consumption should be provided as continuous/routine consumption may result to the bioaccumulation of harmful metals in the body.
\end{abstract}

Key words: Microbiological, heavy metal, spice, yaji, Kano.

\section{INTRODUCTION}

Spices have been used to achieve a certain aroma and taste, as flavoring agents in food since ancient times (Beki and Ulukanli, 2008). Yaji a complex mixture of spices is considered the king of all spice mixtures mostly in the northern part of Nigeria especially among the Hausa Muslim community of Kano State. Yaji can be added to variety of dishes such as soup, rice, beans, roasted or grilled meat, stew, salad, pasta and other meals (Ali, 2011).

Although, spice ingredients are thought to have antimicrobial activity, yet spices are found to have high microbial load of which aerobic bacteria, indicator organisms and some pathogens are the predominant microflora (International Commission on Microbiological Specification for Food) ICMS, (1972). A research carried out by Shamsuddeen (2009) demonstrated that yaji could be contaminated by Salmonella species, Escherichia coli, Clostridium perfringens and Staphylococcus aureus.
According to Peter (2004), a wide variety of fungi including species of Aspergillus, Fusarium and Rhizopus spoil food as they grow readily at low moisture environment. Spiced pepper products pose a major threat to contamination by fungi as they are hygroscopic in nature and highly sensitive to moisture (Kontor, 2015).

Apart from pathogenic microorganisms, one of the major pollution sources that pose some serious health risk and environmental concern results from heavy metals (Duruibe et al., 2007). Moderate levels tend to become accumulated in the tissue of humans thus causing middle term or long term health effects such as chronic asthma, liver damage, insomnia, kidney damage and neurological disorder (Mousuymi and Sarket, 2003). The presence of essential metals like iron, copper, nickel and zinc are very useful for the healthy growth of the body, though very high level s are intolerable. Metals like lead, mercury, cadmium etc are toxic at very low concentrations. These metals may reach and contaminate spices through air, water and soil during preparation and packaging. 
Special Conference Edition, November, 2019

Yaji may serve as a potential vehicle for the transmission of foodborne disease and other health hazards on its consumers, it is of this reason this study was set up with the aim of determining the microbiological and heavy metal quality of yaji sold within Kano metropolis.

\section{MATERIALS AND METHODS Collection of yaji samples}

A total of nine (9) packed samples of yaji were collected randomly from different local retail shops in Kano metropolis and were transported to the Microbiology Laboratory of Bayero University Kano in sterile plastic containers. The complete process of microbiological analysis were performed under sterile conditions to avoid contamination from the environment. Three of the samples includes Yajin daddawa a spice mixture composed of locust beans, chilly, ginger, cloves, masoro (West African pepper), salt and seasoning, another three are yajin tafarnuwar a spice mixture composed of garlic chilly, ginger, cloves, masoro (West African pepper), salt and seasoning, and remaining three are Jan yaji a spice mixture composed of chilly, ginger, cloves, masoro (West African pepper), salt and seasoning without garlic nor locust beans. The samples were subjected to microbiological analysis immediately according to standard procedures (Ugbogu et al., 2018).

\section{Laboratory prepared samples (control)}

Fresh ginger (Zingiber officinale), garlic (Allium sativum), and chilly (Capsicum annuum) were purchased from the market. Locust beans, cloves (Syzygium aromaticum), and masoro (Piper guineense) were also purchased. The fresh ginger, garlic and chilly were properly washed with distilled water, cut into smaller size and oven dried at $60^{\circ} \mathrm{C}$ for 72 hours. After drying, the ginger (208g), garlic (25g), chilly $(200 \mathrm{~g})$, cloves $(16 \mathrm{~g})$ and masoro $(15 \mathrm{~g})$ were mixed together in a large wooden mortar and pounded with a pestle until floury. After pounding, the mixture was sieved to remove larger particles. After sieving, salt and seasoning were added for taste. The mixture were then divided into three parts. Powdered garlic was added to the first portion to form yajin tafarnuwar coded as $Y_{10}$, locust beans was added to the second portion to form yajin daddawa coded as $Y_{11}$, while the third portion was left without adding anything to from jan yaji coded as $Y_{12}$. The samples were then packaged in sterile plastic containers and were transported to the Laboratory of Microbiology, Bayero University Kano for further analysis (Ugbogu et al., 2018).

\section{Sample preparation}

The twelve (12) packed yaji were coded as $Y_{1}$, $Y_{2}, Y_{3}, Y_{4}, Y_{5}, Y_{6}, Y_{7}, Y_{8}, Y_{9}, Y_{10}, Y_{11}$ and $Y_{12}$. They were stored at room temperature until used for analysis.

\section{Serial dilution}

Serial dilution was carried out according to the method described by FAO (1979). Tenfold serial dilution was made for each sample. Twenty five grams of each samples was homogenized in $225 \mathrm{ml}$ of peptone water. This was labelled as $1: 10$ dilution, thus forming the stock solution. Then $10 \mathrm{ml}$ of the stock solution was then transferred into a test tube. Further sequential dilutions were made by taking $1 \mathrm{ml}$ from the $10 \mathrm{ml}$ mixture into other test tubes containing $9 \mathrm{ml}$ of peptone water respectively.

\section{Microbiological analysis}

All of the samples were carried to Microbiology Laboratory in Bayero University Kano for microbiological investigation. Enumeration of Total Mesophilic Bacterial (TMB) count, fungal count, coliform count, isolation and identification of Staphylococcus aureus, Enterobacter, Klebsiella, Salmonella and Shigella were carried out.

\section{Total Aerobic plate count}

This was carried out according to the method of Shamsuddeen (2009). One milliliter $(1 \mathrm{ml})$ of inoculum from $10^{-3}, 10^{-4}$ and, $10^{-5}$ dilutions were transferred into duplicate Petri dishes which were labeled accordingly. This was followed by pouring aseptically about $20 \mathrm{ml}$ of molten nutrient agar. The inoculated plates were mixed by swirling the plates and this was later allowed to solidify. The plates were then incubated at $37^{\circ} \mathrm{C}$ for 24hrs. After incubation, plates containing 30-300 colonies were selected and the colonies were counted and recorded.The average was taken and the number obtained was multiplied by the inverse of the dilution factor. This gave the number of colony forming units per gram of each sample $(c f u / g)$.

\section{Enumeration and isolation of Staphylococcus aureus}

Selective enumeration of Staphylococcus aureus was carried out on spread plates of mannitol salt agar, incubated at $35^{\circ} \mathrm{C}$ for 24hours, representative colonies were purified and stored on NA slants. The presumptive colonies were confirmed on the basis of Mannitol fermentation on Mannitol salt agar, organisms that showed a yellow zone surrounding their growth were isolated onto agar slant for biochemical test (Shamsuddeen, 2009). 
Special Conference Edition, November, 2019 Enumeration and isolation of Coliforms

This was carried out according to the method described by Atlas (1997). In this method, a set up consisting of 9 test tubes each containing $9 \mathrm{ml}$ of lactose broth and an inverted Durham tube were autoclaved to sterilize and expel air. Inoculations were made from the serially diluted samples as follows: From the 1:10 dilution, $1 \mathrm{ml}$ of inoculum was transferred to each of the first three of the 9 test tubes containing $9 \mathrm{ml}$ of lactose broth. Then $1 \mathrm{ml}$ also was transferred from 1:100 dilution to each of the second set of three test tubes of lactose broth and finally $1 \mathrm{ml}$ of inoculum was transferred from 1:1000 dilution to each of the last three tubes. All the 9 test tubes were incubated at $37^{\circ} \mathrm{C}$ for 24 hours and another 24 hours in the absence of gas (presumptive test). Following 24 hours of incubation the tubes were observed for gas production and the number of gas positive tubes were compared with the most probable number (MPN) table to estimate the most probable number of coliforms per gram of sample. Presence of $E$. coli was confirmed by transferring a loop full of inoculum from gas positive tubes into tubes containing $9 \mathrm{ml}$ of Brilliant Green Lactose Broth (BGLB) and were incubated at $37^{\circ} \mathrm{C}$ for 24 hours. Following 24 hours of incubation, the tubes were observed for gas production and a loop full of broth from gas positive tubes were streaked on to Eosin methylene blue (EMB) agar plate and incubated at $37^{\circ} \mathrm{C}$ for 24 hrs. Following incubation, colonies which formed bluish black colour with green metallic sheen, and reddish colonies were noted and isolated on agar slants. This is called the confirmatory test. Also colonies showing metallic sheen on EMB were sub cultured into tubes of lactose broth and incubated at $37^{\circ} \mathrm{C}$. The tubes were observed after 24 hours for gas production to confirm fecal coliform. The presence of $E$. coli and Salmonella were confirmed on the basis of Indole production by using tryptone water and Kovac's reagent strip (Shamsuddeen, 2009).

\section{Fungal count}

This was carried out on PDA (Potato dextrose agar). The plates was identified based on their morphological and cultural characteristics (Mousuymi et al., 2003).

\section{Identification of fungi}

The fungal growths that appeared on the medium were primarily identified using cultural and morphological features. The mold isolates were identified by staining with Lactophenol cotton blue which allows the identification of various fungal structures such as the presence or absence of rhizoids, hyphae, spores as well as other additional structures. Two drops of Lactophenol cotton blue reagent was placed on a clean, grease free glass slide. A small tuft of the fungus was collected using sterile inoculating needle and transferred to the glass slide. A cover slip was placed over the preparation and examined under the microscope using $\times 40$ objective lens (Cheesbrough, 2000).

Determination of heavy metal concentration in the samples

The concentration of $\mathrm{Fe}, \mathrm{Pb}, \mathrm{Zn}, \mathrm{Cu}$, and $\mathrm{Ni}$ in six samples was determined using a Perkin-Elmer model 900 (Precise) Atomic Absorption Spectrophotometer, double beam and deuterium background correction using the procedures contained in the manufacturer's manual (Perkin Elmer, 2005).

\section{RESULTS}

The results of the study are shown in table 1, 2, 3 and 4 respectively. Table 1 shows the total aerobic mesophilic counts, fungal counts and coliform counts of the different yaji samples analyzed. Table 2 and 3 shows the microorganisms isolated from the samples with their percentage frequency of occurrence. Table 4 shows the concentration of metals ( $\mathrm{Pb}, \mathrm{Ni}, \mathrm{Cu}, \mathrm{Zn}$ and $\mathrm{Fe}$ ) in the samples.

Table 1: Total viable counts of bacteria, fungi and coliforms of yaji samples

\begin{tabular}{cccc} 
Sample & TAMC & FC & CC \\
\hline Y1 & $2.91 \times 107$ & $7.40 \times 105$ & 20 \\
Y2 & $>3.00 \times 107$ & $<1.00 \times 103$ & 93 \\
Y3 & $>3.00 \times 107$ & $4.70 \times 106$ & 1100 \\
Y4 & $>3.00 \times 107$ & $9.60 \times 106$ & 3.6 \\
Y5 & $2.10 \times 107$ & $6.55 \times 105$ & 75 \\
Y6 & $1.55 \times 107$ & $<1.00 \times 103$ & 150 \\
Y7 & $>3.00 \times 107$ & $9.75 \times 105$ & 28 \\
Y8 & $>3.00 \times 107$ & $1.10 \times 106$ & 1100 \\
Y9 & $>3.00 \times 107$ & $1.39 \times 106$ & $>1100$ \\
Y10 & $3.35 \times 106$ & $<1.00 \times 103$ & 3.6 \\
Y11 & $3.85 \times 106$ & $<1.00 \times 103$ & 20 \\
Y12 & $4.10 \times 106$ & $<1.00 \times 103$ & 11
\end{tabular}

Key:

TAMC = Total Aerobic Mesophilic Count, FC= Fungal Count, $\mathrm{CC}=$ Coliform Count, $c f u / g=$ coliform forming unit per gram, MPN= Most Probable Number/gram

$\mathrm{Y} 1, \mathrm{Y} 3, \mathrm{Y} 8$, and $\mathrm{Y} 11=$ Spice mixture that contain locust beans (yajin daddawa)

$\mathrm{Y} 2, \mathrm{Y} 7, \mathrm{Y} 5$ and $\mathrm{Y} 12=$ Spice mixture with neither locust beans nor garlic (Jan yaji)

$\mathrm{Y} 4, \mathrm{Y} 9, \mathrm{Y} 6$ and $\mathrm{Y} 10=$ Spice mixture that contains garlic (yaji tafarnuwa) 
Table 2: Percentage frequency of the bacteria isolated from yaji samples

\begin{tabular}{llll}
\hline S/N & Bacteria Isolated & (x)Frequency & \%Frequency \\
\hline 1 & Staphylococcus aureus & 11 & 34.38 \\
2 & Escherichia coli & 10 & 31.25 \\
3 & Klebsiella specie & 5 & 15.25 \\
4 & Enterobacter specie & 3 & 9.38 \\
5 & Salmonella specie & 3 & 9.38 \\
\hline
\end{tabular}

Table 3: Percentage frequency of the fungi isolated from yaji samples

\begin{tabular}{llll}
\hline S/N & Fungi Isolated & (x) Frequency & \%Frequency \\
\hline 1 & Fusarium specie & 3 & 15.00 \\
2 & Rhizopus specie & 5 & 25.00 \\
3 & Aspergillus specie & 12 & 60.00 \\
\hline
\end{tabular}

Table 4: Heavy metal analysis of yaji sourced from some stores in Kano metropolis Heavy metal concentration $(\mathrm{mg} / \mathrm{kg})$

\begin{tabular}{|c|c|c|c|c|c|c|}
\hline \multicolumn{2}{|c|}{ S/No Sample code } & \multirow{2}{*}{$\begin{array}{c}\text { Pb } \\
0.003\end{array}$} & \multirow{2}{*}{$\begin{array}{l}\mathbf{N i} \\
0.002\end{array}$} & \multirow{2}{*}{$\begin{array}{l}\mathbf{C u} \\
0.015\end{array}$} & \multirow{2}{*}{$\begin{array}{l}\text { Zn } \\
0.133\end{array}$} & \multirow{2}{*}{$\begin{array}{l}\text { Fe } \\
0.009\end{array}$} \\
\hline 1 & Y2 & & & & & \\
\hline 2 & Y3 & 0.003 & 0.001 & 0.002 & 0.105 & 0.006 \\
\hline 3 & Y4 & 0.001 & 0.005 & 0.008 & 0.140 & 0.008 \\
\hline 4 & Y7 & 0.001 & 0.004 & 0.011 & 0.147 & 0.004 \\
\hline 5 & Y8 & 0.003 & 0.004 & 0.020 & 0.186 & 0.006 \\
\hline 6 & Y9 & 0.002 & 0.005 & 0.013 & 0.223 & 0.005 \\
\hline \multicolumn{3}{|c|}{ Key: } & \multicolumn{2}{|c|}{$\mathrm{Y} 7=y^{a j i \mathrm{~B}}$} & \multirow{2}{*}{\multicolumn{2}{|c|}{$\begin{array}{l}\mathrm{Pb}=\text { Lead } \\
\mathrm{Zn}=\text { Zinc } \\
\mathrm{Ni}=\text { Nickel }\end{array}$}} \\
\hline \multicolumn{3}{|c|}{$\begin{array}{l}\mathrm{Y} 3=\text { yaji containing locust beans } \mathrm{A} \\
\mathrm{Y} 4=\text { yaji containing garlic } \mathrm{A} \\
\mathrm{Cu}=\text { Copper }\end{array}$} & \multicolumn{2}{|c|}{$\begin{array}{l}\mathrm{Y} 8=\text { yaji containing locust beans } \mathrm{B} \\
\mathrm{Y} 9=\text { yaji containing garlic } \mathrm{B} \\
\mathrm{Fe}=\text { Iron }\end{array}$} & & \\
\hline
\end{tabular}

\section{DISCUSSION}

The aerobic plate counts and fungal counts are high. Some of the values gotten from the result are higher than the maximum acceptable limit stated by the Food and Agricultural Organization (FAO) of the United Nation (2010), according to which the aerobic mesophilic count and fungal counts of spices should not be greater than $10^{6}$ and $10^{4} \mathrm{cfu} / \mathrm{g}$ respectively.

The result of the analysis showed that the samples had an aerobic mesophilic bacterial count, fungal count, and coliform count ranged from $3.35 \times 10^{6}->3.00 \times 10^{7} \mathrm{cfu} / \mathrm{g},<1.00 \times 10^{3}-$ $9.60 \times 10^{6} \mathrm{cfu} / \mathrm{g}$, and $3.6->1100 \mathrm{MPN} / \mathrm{g}$ respectively. This is in line with the work of Shamsuddeen (2009) whose bacterial and fungal counts were in the same range.

The high frequency of Staphylococcus aureus in table II is of concern, since it has been implicated in food borne illnesses due to their ability to produce enterotoxin. The high coliform count and presence of E. coli and Salmonella are indicators of improper and inadequate hygienic practices during preparation (Ugbogu et al., 2018).

The presence of fungal species in yaji samples were also reported by Ugbodu et al. (2018). The fungal species isolated from some of the samples includes Fusarium specie, Rhizopus specie and Aspergillus specie. The presence of these moulds in yaji samples may result in the production of toxic substances which could lead to serious health hazards of the consumers (Adebesin et al., 2001).

The concentration of heavy metals $(\mathrm{Pb}, \mathrm{Ni}, \mathrm{Cu}$, $\mathrm{Zn}$ and $\mathrm{Fe}$ ) in the samples ranges from 0.001 $0.003,0.001-0.005,0.002-0.020,0.105-$ $0.223,0.004-0.009 \mathrm{~g} / \mathrm{kg}$ respectively. Different metals were present in the samples at different levels but all were found to be within the standard limits prescribed by the World Health Organization (WHO, 2003) which recommends that the Provisional Maximum limits in spices for $\mathrm{Pb}, \mathrm{Ni}, \mathrm{Cu}, \mathrm{Zn}$, and $\mathrm{Fe}$ are $0.10,0.05,0.05$, $0.10,0.30 \mathrm{~g} / \mathrm{kg}$ respectively. This is in line with the work of Marian and Cosmos, (2010). 
Special Conference Edition, November, 2019

Yaji may be considered alternate sources of these metals, as they recorded levels below that of the WHO. Zinc is an essential element. Zinc plays an important role in growth and has a recognized action on more than 300 enzymes by participating in their structure or their catalytic and regulatory action. Iron is also an essential element common in humans and plants. They occur in the form of phytate in plants and may also be in the form of inorganic iron salts such as ferric hydroxide.

Lead exposure has been shown to cause severe anemia, permanent brain damage, neurological disorders, reproductive problems, diminished intelligence and a host of other diseases. The relatively high levels of $\mathrm{Pb}$ might have resulted from accumulation of $\mathrm{Pb}$ through air pollution, inclusion or absorption during grinding. And some pesticides, such as lead arsenates, applied during cultivation.

\section{CONCLUSION}

The present study shows that the different combinations of yaji samples are contaminated with bacteria and fungi. These microbial contaminants are of public health significance. Hence, there is need for improvement in the microbial quality of yaji samples sold within

\section{REFERENCES}

Adebesin, A.A., Saromi, O.T., Amusa, N.A. and Fagade, S.O. (2001) Microbial quality of some groundnut products hawked in Bauchi, a Nigerian city. Journal of Food Technology in Africa, 6(2): 53-55

Ali, N.M. (2011). Secrete Ingredients. The new Yorkers. www.thenewyokers.com (accessed 2018 march 13)

Atlas, R. M. (1997). Principles of Microbiology. Second edition C. Brown publishers. Pp. 802-803.

Beki, I. and Ulakanli. Z. (2008) Enumeration Of Microorganisms And Detection Of Some Pathogens In Commonly Used Spices Sold Openly From Retail Stores In Kars G.U. Journal Of Science, 21(3):79-85.

Cheesbrough, M. 2000. District laboratory practice in tropical countries. Low price ed., Cambridge University Press, London, England, UK, pp. 64-90.

Duruibe, J.O., Ogwuegbe, M.O.C. and Egwurugwu, J.N. (2007). Heavy Metal Pollution and Human Bio Toxic Effects. International Journal of Physical Science, 2(5):112-118.

FNB (Food and Nutrition Board) (2001) Institute of Medicine. Iron Dietary Reference Intakes For Vitamin A, Vitamin K, Boron, Chromium, Copper, Iodine, Iron,
Kano metropolis. The heavy metals analyzed from this work provides information about the concentration of metals in yaji which can be related to industrial, agricultural and other human activities taking place in Kano. All the heavy metal levels remain within their permissible safe levels for human consumption as laid down by WHO (2003).

\section{RECOMMENDATION}

1. Yaji should be produced and stored under strict hygienic conditions to avoid the introduction of undesirable organisms, and toxic metals which may bring about contamination, spoilage and health problems.

2. Immediate action should be taken to insure the application of good agricultural and manufacturing practices to prevent fungal and heavy metal contamination in spice and spice products like yaji by using different methods to minimize contamination.

3. Storage conditions such as moisture and temperature should be controlled on both the raw materials used in yaji production and the final product (yaji).

Manganese, Molybdenum, Nickel, Silicon, Vanadium, And Zinc. Washington D.C: National Academy Press. 290-393.

Food and Agricultural Organization of the United Nation FAO (1979): Manuals of food quality and control 4. Microbiological analysis. D1-D37.

International Commission of Microbiological Specification for Food (ICMSF). 1982. Microorganisms in foods. Vol. 1: Their significance and methods of enumeration $2^{\text {nd }}$ ed., F.S. Thatcher and D.S. Clark (Eds.). University of Toronto Press, Toronto, ON, Canada, pp. 19-30.

International Standard Organization, (ISO) (1972). Spices and condiments. Women culture Finchized Draft Proposal. Tc34/Sc-7, 150 Budapest.

Kontor, K. (2015). Quality Characteristics of Pepper Powder As Influenced By Packaging and Storage Duration. Kwame Nkrumah University of Science and Technology Kumasi.

Mariam, A.N. and Cosmos, O.A. 2010. Heavy Metal Content of Some Common Spices Available in Markets in the Kumasi Metropolis of Ghana. American Journal of Scientific and Industrial Research, 1(2): 158-163. 
Special Conference Edition, November, 2019

Mead, P.S., Slutsker, L., Dietz, V., McGaig, L. F., Bresee, J. S., Shapiro, C., Griffin, P.M., and Tauxe, R. V. 1999. Food-related illness and death in the United States. Emergence of Infectious diseases. 5:607-625.

Mousuymi, B. And Sarkat, P.K. (2003). Microbiological Quality of Some Retail Spices in India. International Food Research. 36:469-474.

Peter, K.V. (2004). Handbook of Spices. Vol.2. Abington; Wood Head Publishing Limited. PP. 15-20.

Peter, N., Menasherov, M., Ravid, U. And Juven, B. (1995). Antifungal Activity Of Oregana And Thyme Essential Oils Applied As Fumigants Against Fungi Attacking Stored Grain. Journal of Food Protection. 58: 81-85.
Ugbogu, O.C., Ogodo, A.C. and Ameh, B.O. 2018. Some Microorganisms Associated With Ginger Based Yaji in Wukari Metropolis. International Food Research Journal, 25(4): 1703 - 1707.

Shamsuddeen U. (2009) Microbiological quality of spices used in the production of Kilishi a traditionally dried and grilled meat product. Bayero Journal of Pure and Applied Sciences, 2(2): 66-69.

WHO (2003): Joint FAU/ WHO Expert Committee on Food Additives and Contaminants. Sixty First Meeting Summary and Conclusions Www.Ftp://Ftp.Fao.Org/Es/Esn/Jecfa/Je cfa6isc.Pdf (Accessed 2018 March 11). 